\title{
Plasma Opioids in the First Hours of Life
}

\author{
F. FACCHINETTI, ${ }^{(40)}$ F. BAGNOLI, R. BRACCI, AND A. R. GENAZZANI \\ Clinica Ostetrica e Ginecologica [F.F.], University of Siena, Cattedra di Neonatologia [F.B., R.B.J, University of \\ Siena, Cattedra di Patologia Ostetrica e Ginecologica [A.R.G.], University of Cagliari, Italy
}

\section{Summary}

High concentrations of ACTH are present in the neonatal circulation in response to birth stress. Since ACTH and $\beta$-lipotropin $(\beta L P H)$ have a common precursor, and $A C T H$ and $\beta$-endorphin $(\beta E P)$ are released in parallel in stressful situations, we measured plasma levels of $\beta \mathrm{LPH}$ and $\beta \mathrm{EP}$ in the first 24 hours of life.

Blood samples were taken from the umbilical cord at birth in 27 neonates, subdivided into four groups.

A further blood sample was obtained from the jugular vein after 30 min in nine cases (group A), after 6 hours in six (group B), and after 12 hours in six (group C), and after 24 hours in six (group D).

$\beta$ LPH and $\beta$ EP were measured by specific radioimmunoassays after silicic acid extraction of the plasma and Sephadex G-75 column chromatography.

In cord plasma, the mean ( \pm S.E.) $\beta$ LPH concentrations (pg/ $\mathrm{ml}$ ) varied between $219.5 \pm 84.5$ (group $D$ ) and $241 \pm 43.3$ (group $B$ ), while those of $\beta E P$ ranged between $70.2 \pm 8.2$ (group $C$ ) and $54.6 \pm 14.4$ (group $D$ ). The $\beta \mathrm{LPH} / \beta$ EP ratio on a molar basis ranged from $1.12 \pm 0.73$ (group $A$ ) to $1.37 \pm 0.60$ (group $C$ ).

Plasma $\beta$ LPH concentrations determined at 30 min were 199.1 \pm 50.4 , and these declined slightly in group $C$ (after 12 hours: 168.2 \pm 30.2 ), but only showed a significant fall after 24 hours (88.5 $\pm 27.0 ; P<0.01$ in comparison with the previous groups), reaching normal adult levels $(71.7 \pm 25.1)$.

The pattern of $\beta E P$ plasma levels $(\mathrm{pg} / \mathrm{ml})$ was very similar to that reported for $\beta$ LPH. $\beta$ EP plasma levels only showed a significant decrease after 24 hours $(22.7 \pm 8.9 ; P<0.01)$ when compared to the 12-hour age group $\mathrm{C}$. $\beta \mathrm{EP}$ concentrations at 30 $\min (76.1 \pm 47.7), 6$ hours $(68.6 \pm 29.3)$, and 12 hours $(51.8 \pm$ 18.1) of life did not differ significantly from those found in mixed cord blood and were constantly higher than normal adult levels $[24.5 \pm 12.3]$.

Since the half-life of $\beta L P H$ and $\beta E P$ is respectively 45 and 37 min, the present data demonstrate that neonates are able to release $\beta \mathrm{LPH}$ and $\beta$ EP during the first hours of life. Both these molecules may contribute to help the newborn in the transition from a close dependence on the mother, to an autonomous existence.

\section{Speculation}

Although the physiologic role of circulating $\beta \mathrm{LPH}$ and $\beta \mathrm{EP}$ has not been fully clarified, the presence of these peptides in neonatal plasma could represent an important analgesic factor in overcoming birth stress. Thus, an abnormal presence of these substances could be related to pathological situations. However, the source, the regulatory mechanisms and the biologic effects of circulating opioids in neonatal life are still unclear and require further investigation.

The transition from intra- to extra-uterine life is probably the most stressful situation that is met during our existence, and many adaptive phenomena are required to overcome this critical period.
In particular, an early activation of the hypothalamus-pituitaryadrenal axis is necessary.

The significantly lower plasma cortisol levels found in newborn babies delivered by elective caesarian section, when compared with vaginally delivered neonates, demonstrates the relation between stimulation of the adrenal gland and the stressful events of labour and delivery $(5,35)$.

Furthermore, it has recently been demonstrated that ACTH plasma levels are elevated during the first 6 hours of life, declining to normal adult values only 18 hours later $(4,20)$. Accordingly, many authors have observed high plasma cortisol levels during the first 3 hours of life $(1,15,16,19,33)$, which decrease to normal adult levels after 24-48 hours.

The ability of neonates to secrete cortisol in response to ACTH stimulation $(15,18)$ or during insulin-induced hypoglycemia (1) and plasma ACTH suppression after dexamethasone, suggest that a Corticotropin Releasing Factor (CRF)-mediated cortisol-ACTH feedback mechanism is present in the neonatal period.

On the other hand, the ACTH molecule in the anterior pituitary is contained in a large molecular weight precursor, the pro-opiocortin (25) which also includes the aminoacid sequences of $\gamma$ MSH and $\beta$-lipotropin ( $\beta \mathrm{LPH})$. In adults, ACTH, $\beta \mathrm{LPH}$, and $\beta$ endorphin ( $\beta \mathrm{EP})$ (C-terminal residue of $\beta \mathrm{LPH} ; \beta \mathrm{LPH} 61-91)$ are secreted concomitantly in stressful situations $(14,21)$. On this basis, and considering the very high amounts of ACTH $(7,11$, $39), \beta \mathrm{LPH}$ and $\beta \mathrm{EP}(7,9,12,13,27)$ which circulate in the maternal and cord plasma at delivery, we investigated the changes occurring in $\beta \mathrm{LPH}$ and $\beta \mathrm{EP}$ plasma levels during the first few hours of life.

\section{MATERIALS AND METHODS}

\section{SUBJECTS}

After informed consent of the parents, 27 neonates, whose mothers were suspected of having contracted an infectious disease during pregnancy or who presented $\mathrm{Rh}$ incompatibility and in whom a blood sample was required for routine analysis, were considered in this study.

Gestational age ranged between 38 and $40 \mathrm{wk}$, the 1-min Agpar score between 8 and 10, and neonatal weight ranged from 2750 to $4000 \mathrm{~g}$.

Mixed cord blood was collected in all cases at delivery and a second sample was taken from the jugular vein after $30 \mathrm{~min}$ in nine cases, after 6 hours in six, after 12 hours in six, and after 24 in the remaining six subjects. A further sample was also taken after 24 hours in three of the neonates from whom second samples had been taken at 6 hours, because of suspected (although not confirmed) hypocalcemia.

Heparinized blood samples of 3-4 ml, with the addition of 500 KIU Trasylol, were centrifuged immediately after collection at $2000 \mathrm{~g}$ at $4^{\circ} \mathrm{C}$ for $15 \mathrm{~min}$; the plasma was stored at $-70^{\circ} \mathrm{C}$ and assays were performed within 2 months.

\section{PLASMA PURIFICATION}

Plasma, 1.5 to $3 \mathrm{ml}$, was extracted with $100-200 \mathrm{mg}$ silicic acid (100 mesh) on a rotary mixer for 1 hour. After washing with water 
and $1 \mathrm{~N}$ hydrochloric acid, the silicic acid was extracted twice with $1 \mathrm{ml}$ of acetone- $1 \mathrm{~N} \mathrm{HCl}(9: 1)$.

The acetone mixture was dried under nitrogen, redissolved in $0.5 \mathrm{ml}$ of $0.1 \mathrm{M}$ acetic acid, $0.01 \%$ bovine serum albumin and applied to a Sephadex G-75 column $(1.5 \times 45 \mathrm{~cm})$ eluted with the same solution. In these conditions, standard $\beta \mathrm{LPH}$ and $\beta \mathrm{EP}$, added to dexamethasone-treated plasma, gave partition coefficients (Kav) of 0.54 for $\beta \mathrm{LPH}$ and 0.82 for $\beta \mathrm{EP}$. In these conditions, two distinct peaks containing respectively $\beta \mathrm{LPH}$ and $\beta \mathrm{EP}$ were collected from each chromatographed plasma extract; $10-15$ $\mathrm{ml}$ of eluates were pooled, freeze-dried, and redissolved in $0.4 \mathrm{ml}$ of $0.05 \mathrm{M}$ phosphate buffer $\mathrm{pH} 7.4$, to be tested by radioimmunoassay (RIA) (8).

Since the molecular weight of $\gamma$-lipotropin $(1-58 \beta \mathrm{LPH})$ is near 6300 and its tertiary structure is similar to $\beta \mathrm{LPH}$, this peptide can be expected to elute in an intermediate position between $\beta \mathrm{LPH}$ and $\beta$ EP peaks, and that an aliquot of endogenous $\gamma L P H$ will be present in the $\beta$ LPH fraction to be measured by RIA.

Cold $\beta \mathrm{LPH}$ and $\beta \mathrm{EP}, 0.5 \mathrm{ng}$, added to 24 plasma samples, were recovered in the order of $51.2 \pm 7.4$ and $57.5 \pm 8.1 \%$ (mean \pm S.D.), respectively. Twelve Sephadex columns were eluted simultaneously through a multi-channel peristaltic pump and $\mathrm{I}^{125}-\beta \mathrm{LPH}$ and $\beta$-EP were added to one plasma sample in order to monitor the recovery in each series of extraction and chromatography.

\section{RIA}

Synthetic $\beta$ EP (Bachem Inc., Torrance, CA) and Human $\beta$ LPH (donated by Prof. C. H. Li, San Francisco, CA) were used as standard and for labelling with $\mathrm{I}^{125}$ using the Chloramine-T method.

Anti-human $\beta E P$ rabbit serum (C-terminal) and anti-human LPH rabbit serum (N-terminal), both supplied by Prof. C. H. Li, were used at dilutions of $1: 3400$ and $1: 5400$, respectively.

Cross-reactivities of the antisera have been reported elsewhere $(37,38)$.

Since $\gamma \mathrm{LPH}$ probably cross-reacts completely with $\mathrm{N}$-terminal anti- $\beta$ LPH serum, $\gamma \mathrm{LPH}$ present in the pooled $\beta \mathrm{LPH}$ fraction obtained by column chromatography may contribute to the amount of IR $\beta \mathrm{LPH}$ apparently measured. Nevertheless, the IR materials present in this fraction and tested with the above described $\beta$ LPH RIA, will conventionally be referred to as $\beta \mathrm{LPH}$.

Two dcuble-antibody RIAs were performed as described elsewhere (8).

Sensitivity of the assays was $10 \mathrm{pg}$ for $\beta \mathrm{LPH}$ and $4.5 \mathrm{pg}$ for $\beta E P$. Intra- and inter-assay coefficients of variation were respectively 8.4 and 10.6 for $\beta \mathrm{LPH}$ and 7.6 and 11.2 for $\beta \mathrm{EP}$.

\section{RESULTS}

Figure 1 reports the plasma levels of $\beta \mathrm{LPH}, \beta \mathrm{EP}$ and their molar ratio, found in the 27 neonates subdivided into four groups according to neonatal age, and respective cord blood concentrations. The mean ( \pm S.D.) $\beta$ LPH concentrations in cord plasma in the four groups ranged from $219.5 \pm 84.5$ to $241 \pm 43.3 \mathrm{pg} / \mathrm{ml}$, while single values ranged from 102 to $342 \mathrm{pg} / \mathrm{ml}$. Plasma concentrations in the neonates diminished from $199.1 \pm 50.4 \mathrm{pg} / \mathrm{ml}$ (range: $102-283 \mathrm{pg} / \mathrm{ml}$ ) after $30 \mathrm{~min}$, to $168.2 \pm 30.3 \mathrm{pg} / \mathrm{ml}$ (range: $105-310 \mathrm{pg} / \mathrm{ml}$ ) after 12 hours, and $88.5 \pm 27.0 \mathrm{pg} / \mathrm{ml}$ (range: $140-294 \mathrm{pg} / \mathrm{ml}$ ) after 24 hours. Only the levels found after this interval of time showed a significant difference $(P<0.01)$ in comparison to both the respective cord plasma concentration and the plasma levels found in the group tested after 12 hours $(P<$ $0.05)$.

The mean ( \pm S.D.) $\beta$ EP concentration in cord plasma varied in the four groups from $70.2 \pm 8.2$ to $54.6 \pm 14.4 \mathrm{pg} / \mathrm{ml}$, while single values ranged between 14 and $101 \mathrm{pg} / \mathrm{ml}$. Plasma levels of $\beta E P$ in the neonates decreased from $76.1 \pm 47.7 \mathrm{pg} / \mathrm{ml}$ (range: $18-176$ $\mathrm{pg} / \mathrm{ml}$ ) at $30 \mathrm{~min}$, to $66.6 \pm 29.3 \mathrm{pg} / \mathrm{ml}$ (range: $35-109 \mathrm{pg} / \mathrm{ml}$ ) at 6 hours, $51.8 \pm 18.1 \mathrm{pg} / \mathrm{ml}$ (range: $33-79 \mathrm{pg} / \mathrm{ml}$ ) at 12 hours, and $27.7 \pm 8.9 \mathrm{pg} / \mathrm{ml}$ (range: $17-38 \mathrm{pg} / \mathrm{ml}$ ) after 24 hours. These last values were significantly lower $(P<0.01)$ than the respective $\beta \mathrm{EP}$ cord plasma concentrations $(54.5 \pm 14.4 \mathrm{pg} / \mathrm{ml})$ and those found in neonates after 12 hours $(P<0.05)$.

The $\beta \mathrm{LPH} / \beta \mathrm{EP}$ ratio on a molar basis ranged from $1.12 \pm 0.37$ to $1.37 \pm 0.60$ in the four groups of cord plasma, and in the neonatal plasma from $1.22 \pm 0.63$ to $1.13 \pm 0.36$. A significant correlation between $\beta \mathrm{LPH}$ and $\beta \mathrm{EP}$ plasma levels was found both in cord plasma $(\mathrm{r}=0.492 ; P<0.01)$ and in neonatal plasma $(\mathrm{r}$ $=0.780 ; P<0.001)$.

Individual plasma levels of the two opioids obtained in the three cases in which two successive samples were taken, are reported in Table 1 . These results support the above reported $\beta \mathrm{LPH}$ and $\beta \mathrm{EP}$ patterns in the early hours of neonatal life.

\section{DISCUSSION}

With the exception of Goland et al. (13) who found constantly normal levels of $\beta E P$-like immunoreactive materials, plasma concentrations of $\beta \mathrm{EP}$ have been shown to increase progressively during pregnancy, the highest levels being found at term $(7,12)$. A further increase has been observed in the first and second stages of labour $(7,9,13)$, when $\beta$ LPH plasma levels also rise in parallel.

High concentrations of both opioids have been demonstrated in mixed cord plasma $(7,9,12,13)$ with a positive gradient from the umbilical artery to vein (36).

The origin of these opioids in the maternal circulation could be attributed not only to the pituitary, but also to the placenta, since the presence $(11,28)$ and the in vitro synthesis and release $(23)$ of both $\beta$ LPH and $\beta E P$ have been demonstrated by this endocrine organ. Moreover, in addition to the ability of the fetal pituitary to secrete ACTH (2), immunocytochemical studies have recently demonstrated that fetal anterior pituitary granules contain $\beta \mathrm{LPH}$, $\beta E P$ and probably the proopiocortin (22).

The presence in the neonatal circulation, up to the twelfth hour of life, of elevated $\beta \mathrm{LPH}$ and $\beta$ EP values which are similar to those found in cord plasma, seems to indicate that the neonate is able to release these peptides. In fact, the half-life of $\beta \mathrm{LPH}$ and $\beta E P$, calculated as time of disappearance from the plasma, is 45 and 37 minutes, respectively (10). Therefore, if the opioid peptides found in neonates originate from the placental tissue or maternal plasma, it may be expected that they will have disappeared from the circulation after 6 hours.

On the other hand, these data are in perfect agreement with previous demonstrations of raised ACTH levels during the first 6 hours of life $(4,20)$, and offer further support to the concept that $\mathrm{ACTH}, \beta \mathrm{LPH}$, and $\beta \mathrm{EP}$ are released in parallel in stressful situations $(14,25)$.

The hypothesis that not only delivery, but also the first hours of extrauterine life may represent a stressful situation, is further supported by the marked metabolic changes occurring at this time, such as hypoglycemia (6), hyponatremia (32), hypocalcemia (30), loss of liquids, etc. These observations also support the supposition that the adrenal hyperactivity found in this critical period is sustained $(1,18,19,23)$ by the high levels of ACTH. On the other hand, the demonstration that $\beta E P$ stimulates corticosterone release by rat adrenal cells in vitro (3), and that $\beta \mathrm{LPH}$ induces aldosterone production by human adrenal cells in culture (26), suggest that $\beta \mathrm{LPH}$ and $\beta \mathrm{EP}$ may also be involved in the adrenal stimulation occurring in the postnatal period.

However, the physiologic significance of the high $\beta \mathrm{LPH}$ and $\beta E P$ levels at birth and during the first few hours of life still remains unclear.

In consideration of the fact that a significant amount of pituitary hormonal secretion may reach the central nervous system by backflow (29), we can assume [bearing in mind the possible extrapituitary sources of these peptides (3)], that circulating levels could also partially reflect their central effects. Therefore, the three times higher than normal $\beta E P$ levels found in early postnatal life could play a role in mediating neonatal analgesia which is probably fundamental in overcoming the painful situation of delivery and birth. In fact, it has been shown that $\beta E P$ in pharmacologic doses possesses a marked analgesic activity when administered both intraventricularly (24) and peripherally (34) in animals, and more 

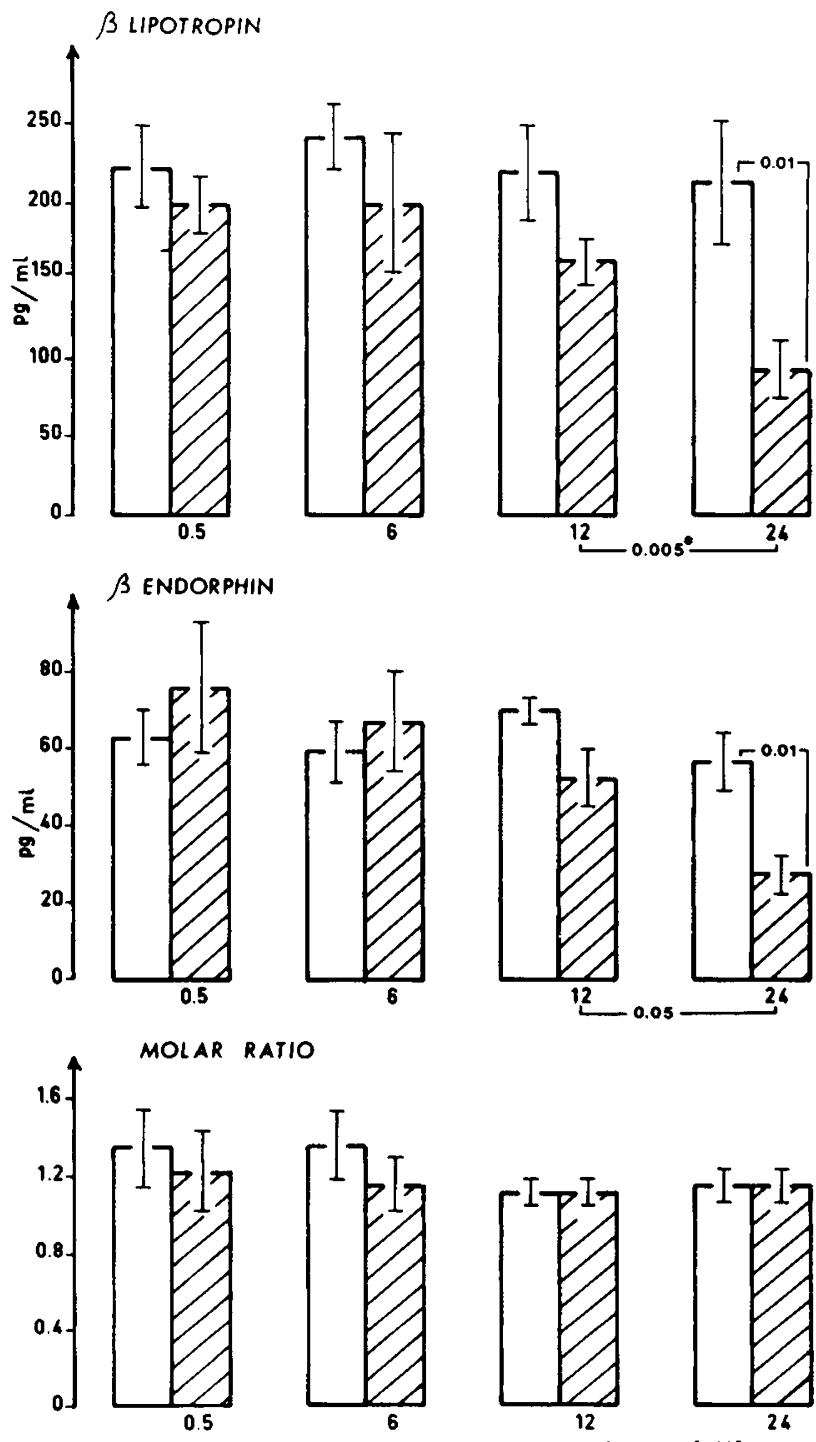

Fig. 1. Plasma levels of $\beta$-lipotropin and $\beta$-endorphin and their ratio on a molar basis, determined in the four groups of neonates at different hours of life. Opioid concentrations (shaded bars) are reported for each group, together with the respective mixed cord plasma levels at birth. The statistical analysis is reported.

Table 1. $\beta$-Lipotropin and $\beta$-endorphin concentrations $(\mathrm{pg} / \mathrm{ml})$ in mixed cord plasma (MCP) and after 6 and 24 hours of life, in three cases studied longitudinally

\begin{tabular}{lcccccccc}
\hline & \multicolumn{3}{c}{$\beta$-lipotropin } & & \multicolumn{3}{c}{$\beta$-endorphin } \\
\cline { 2 - 5 } \cline { 6 - 8 } Case & MCP & 6 & 24 & & MCP & 6 & 24 \\
\hline BG & 271 & 222 & 97 & & 85 & 66 & 31 \\
MF & 294 & 211 & 65 & & 54 & 45 & 31 \\
RC & 211 & 147 & 78 & & 66 & 51 & 25 \\
\hline
\end{tabular}

recently pain relief has been demonstrated in humans by intravenous injection of $\beta E P$ (17).

In conclusion, the present data demonstrate that neonates are able to release $\beta \mathrm{LPH}$ and $\beta \mathrm{EP}$ during the first hours of life. Both these molecules may contribute to help the neonate in the transition from a close dependence on the mother to an autonomous existence.

\section{REFERENCES AND NOTES}

1. Akimasa, O., Nishimura, Y., and Kawarazaki, T.: Changes in plasma 11-hydroxycorticosteroids after ACTH, Insulin and Dexamethasone in neonatal infants. J. Clin. Endopcrinol., 34: 516 (1972).

2. Arai, K., Yanaihara, T., and Okinaga, S.: Adrenocorticotrophic hormone in human fetal blood at delivery. Am. J. Obstet. Gynecol., 125: 1136 (1976).
3. Bruni, J. F., Watkins, W. D., and Yen, S. S. C.: $\beta$-Endorphin in the human pancreas. J. Clin. Endocrinol. Metab., 49: 649 (1979).

4. Cacciari, E., Cicognani, A., Pirazoli, P., Dallacasa, P., Mazzaracchio, M. A., Tassoni, P., Bernardi, F., Salardi, S., and Zappulla, F.: GH, ACTH, LH and FSH behaviour in the first seven days of life. Acta Paediatr. Scand., 65: 337 (1976).

5. Campbell, A. L., and Murphy, B. E. P.: The maternal-fetal cortisol gradient during pregnancy and at delivery. J. Clin. Endocrinol. Metabl., 45: 435 (1977).

6. Cornblath, M., and Reisner, S. H.: Blood glucose in the neonate and its clinical significance. N. Engl. J. Med., 273: 378 (1965).

7. Csontos, F., Rust, M., Hollt, V.. Mahr, W., Kromer, W., and Teschemacher, H. J.: Elevated plasma $\beta$ EP levels in pregnant women and their neonates. Life Sci., 25: 835 (1979).

8. Facchinetti, F., and Genazzani, A. R.: Simultaneous radioimmunoassay of $\beta$ LPH and $\beta$ EP in human plasma. In: A. Albertini, M. Da Prada, B. A. Peskar: Radioimmunoassay of Drugs and Hormones in Cardiovascular Medicine. pp. 347-354 (Elsevier/North Holland Biomedical Press, Amsterdam, 1979).

9. Fletcher, J. E., Thomas, T. A., and Hill, R. G.: $\beta E P$ and parturition. Lancet, 1 : $310(1980)$

10. Foley, K. M., Kourides, I. A., Inturrisi, C. E.. Kaiko, R. G., Zaroulis, C. G.. Posner, J. B., Houde, R. W., and Li, C. H.: $\beta E P$ : analgesic and hormonal effects in humans. Proc. Nat. Acad. Sci. USA, $78: 5377$ (1979).

11. Genazzani, A. R., Fraioli, F., Hurlimann, J., Fioretti, P., and Felber, J. P. Immunoreactive $\mathrm{ACTH}$ and cortisol plasma levels during pregnancy: detection and partial purification of corticotropin-like placental hormone: human chorionic corticotropin. Clin. Endocrinol., 4: 1 (1975).

12. Genazzani, A. R., Tarli, P., Fraioli, F., Facchinetti. F., Pallini, R., and Massafra, C.: Partial purification of $\beta \mathrm{LPH}$ and $\beta$ EP from human placental extracts and plasma levels during pregnancy. In: A. Klopper, A. R. Genazzani, P. G. Crosignani: Human Placenta: Proteins and Hormones. pp. 467-478 (Academic Press, London, 1980) 
13. Goland, R. S., Wardlaw, S. L., Stark, R. I., and Frantz, A. G.: Human plasma Bendorphin during pregnancy, labor and delivery. J. Clin. Endocrinol. Metab. 52: 74 (1981).

14. Guillemin, R., Vargo, T., Rossier, J., Minick, S., Ling, N., Rivier, C., Vale, W., and Bloom, F.: $\beta$ EP and adrenocorticotropin are secreted concomitantly by the pituitary gland. Science, 197: 1367 (1977).

15. Gutai, J., George. R., Koeff. S., and Bacon. G. E.: Adrenal response to physical stress and the effect of adrenocorticotropic hormone in newborn infants. J. Pediatr., 81: 719 (1972).

16. Hillman, D. A., and Giroud, J. P.: Plasma cortisone and cortisol levels at birth and during the neonatal period. J. Clin. Endocrinol. Metab., 25: 243 (1965).

17. Hosobuchi, Y., and Li, C. H.: The analgesic activity of human $\beta$-endorphin in man. Commun. Psychopharmacol., 2: 33 (1978)

18. Hughes, E. R., Seely, J. R., Kelley, V. C., and Ely, R. S.: Corticosteroid levels before and after corticotropin. J. Pediatr., 104: 605 (1962).

19. Kauppila, A.. Koivisto, M.. Pukka. M., and Tuimala, R.: Umbilical cord and neonatal cortisol levels. Effect of gestational and neonatal factors. Obstet. Gynecol.. 52: 666 (1978).

20. Kauppila, A., Simila, S., Ylikorkala, O., Koivisto, M., Makela, P., and Haapalahti, J.: ACTH levels in maternal, fetal and neonatal plasma after short-term prenatal dexamethasone therapy. Br. J. Obstet. Gynaecol., 84: 124 (1976).

21. Krieger, D. T., Liotta, A., Suda, T., Goodgold, A. N., and Condon, E.: Human plasma immunoreactive $\beta \mathrm{LPH}$ and adrenocorticotropin in normal subjects and in patients with pituitary-adrenal disease. J. Clin. Endocrinol. Metab., 48: 566 (1979).

22. Li, J. Y., Dubois, M. P., and Dubois, P. M.: Ultrastructural localization of immunoreactive corticotropin, $\beta$-lipotropin, $\alpha$ - and $\beta$-endorphin in cells of the human fetal anterior pituitary. Cell Tissue Res., 204: 37 (1979).

23. Liotta, A., and Krieger, D. T.: Biosynthetic pathway of ACTH and related peptides of the human placenta: in vitro demonstration. In: A. Klopper, A. R. Genazzani, P. G. Crosignani: Human Placenta: Proteins and Hormones. pp. 267-282 (Academic Press, London, 1980).

24. Loh, H. H., Tseng. L. F., Wei, E., and Li, C. H.: $\beta$-Endorphin is a potent analgesic agent. Proc. Nat. Acad. Sci. USA. 73: 2895 (1976).

25. Mains, R. E., Eipper, B. A., and Ling, N.: Common precursor to corticotropins and endorphins. Proc. Nat. Acad. Sci. USA, 74: 3014 (1977).

26. Matsuoka, H., Mulrow, P. J., and Li, C. H.: $\beta$-Lipotropin: a new aldosteronestimulating factor. Science, 209: 307 (1980).

27. Nakai, Y., Nakao, K., Oki, S., and Imura, H.: Presence of immunoreactive $\beta$ LPH

Copyright $(1) 1982$ International Pediatric Research Foundation, Inc. 0031-3998/82/1602-0095\$02.00/0 and $\beta E P$ in human placenta. Life Sci., 23: 2013 (1978).

28. Nakao, K., Nakai, Y., Oki, S., Horii, K., and Imura, H.: Presence of immunoreactive $\beta \mathrm{EP}$ in normal human plasma. J. Clin. Invest., 62: 1395 (1978).

29. Oliver, C., Mical, R. S., and Porter, J. C.: Hypothalamic-pituitary vasculature: evidence for retrograde blood flow in the pituitary stalk. Endocrinology, 101 598 (1977).

30. Schedewie, H. K., and Fisher, D. A.: Perinatal mineral homeostasis. In: D. Tulchinsky, K. J. Ryan: Maternal-fetal Endocrinology. pp. 355-368 (W. B. Saunders Company, Philadelphia, 1980).

31. Shanker, G., and Sharma, R. K.: $\beta$-Endorphin stimulates corticosterone synthesis in isolated rat adrenal cells. Biochem. Biophys. Res. Commun., 86: 1 (1979).

32. Siegel, S. R., Fisher, D. A., and Oh, W.: Serum aldosterone concentrations related to sodium balance in the newborn infant. Pediatrics, 53: 410 (1974).

33. Sippel, W. G., Becker, H., Versmold, H. T., Bidlingmaier, F., and Knorr, D.: Longitudinal studies of plasma aldosterone, corticosterone, deoxycorticosterone, progesterone, 17-hydroxyprogesterone, cortisol and cortisone determined simultaneously in mother and child at birth and during the early neonatal period. I. Spontaneous delivery. J. Clin. Endocrinol. Metab., 46: 971 (1978).

34. Tseng, L. F., Loh, H. H., and Li, C. H.: $\beta$-Endorphin as a potent analgesic by intravenous injection. Nature, 263: 239 (1976).

35. Vermes, I., Kaitar. I., and Szabo, F.: Changes of maternal and fetal pituitaryadrenocortical functions during human labour. Horm. Res., 11: 213 (1979).

36. Wardlaw, S. L., Stark, R. I., Baxi, L., and Frantz, A. G.: Plasma $\beta$-endorphin and $\beta$-lipotropin in the human fetus at delivery: correlation with arterial $\mathrm{pH}$ and $\mathrm{pO}_{2}$. J. Clin. Endocrinol. Metab. 49: 888 (1979).

37. Wiedemann, E., Saito, T., Linfoot, J. A., and Li, C. H.: RIA of human $\beta$ LPH in unextracted plasma. J. Clin. Endocrinol. Metab., 45: 1108 (1977).

38. Wiedemann, E., Saito, T., Linfoot, J. A., and Li, C. H.: Specific RIA of human $\beta E P$ in unextracted plasma. J. Clin. Endocrinol. Metab., 49: 478 (1979).

39. Winters, A. J., Oliver, C., Colston, C., MacDonald, P. C., and Porter, J. C.: Plasma ACTH levels in the human fetus and neonate as related to age and parturition. J. Clin. Endocrinol. Metab., 39: 269 (1974).

40. Requests for reprints should be addressed to: Dr. F. Facchinetti, Cattedra di Patologia Ostetrica, Clinica Pediatrica, via Porcell, 09100 Cagliari, Italy.

41. This research was supported in part by the C.N.R. Project "Biology of Reproduction".

42. Received for publication February 11, 1981.

43. Accepted for publication May 1, 1981

Printed in U.S.A. 